\title{
SMALL HEAT SHOCK PROTEIN RESPONSES OF A CLOSELY RELATED PAIR OF DESERT AND COASTAL ENCELIA
}

\author{
Charles A. Knight ${ }^{1, *}+$ and David D. Ackerly* \\ *Department of Biological Sciences, Stanford University, Stanford, California 94305, U.S.A.; and tDepartment of Genetics and Evolution, \\ Max Planck Institute of Chemical Ecology, D-07745 Jena, Germany
}

\begin{abstract}
Evolutionary variation for accumulation of small heat shock protein (sHsp) may contribute to thermal niche differentiation between species. Here we examine temperature and time-course-dependent variation for $\mathrm{sHsp}$ accumulation in a recently diverged pair of Encelia raised in a common environment: Encelia farinosa, common in the Mojave desert, and Encelia californica, which is found along the cool coastal bluffs of southern North America. Both species exhibit peak sHsp accumulation at $42^{\circ} \mathrm{C}$. Encelia californica accumulated greater levels of sHsp at temperatures below $42^{\circ} \mathrm{C}$, while E. farinosa had greater levels above $42^{\circ} \mathrm{C}$. Encelia farinosa accumulates sHsp at temperatures up to $45^{\circ} \mathrm{C}$, while E. californica does not synthesize sHsp above $44^{\circ} \mathrm{C}$. Both species accumulated significant levels of $\mathrm{sHsp}$ while maintaining photosynthetic electron transport $\left(F_{\mathrm{v}} / F_{\mathrm{m}}\right)$, but above the temperatures that elicited peak $\mathrm{sHsp}$ expression, levels of $\mathrm{sHsp}$ and $F_{\mathrm{v}} / F_{\mathrm{m}}$ declined in parallel to zero. Encelia californica accumulated greater levels of sHsp more rapidly than E. farinosa following a $15 \mathrm{~min}$, $42^{\circ} \mathrm{C}$ heat treatment; however, E. farinosa maintained greater $F_{\mathrm{v}} / F_{\mathrm{m}}$ at all time points. Our results indicate that there are significant differences between Encelia species for $\mathrm{sHsp}$ accumulation but that these results depend on the duration, magnitude, and recovery time following temperature stress.
\end{abstract}

Keywords: thermal tolerance, evolution, temperature stress, fluorescence, photosynthesis, $F_{\mathrm{v}} / F_{\mathrm{m}}$.

\section{Introduction}

Small heat shock proteins (sHsps) often dominate protein synthesis during and after high temperature stress and under some conditions can rapidly accumulate to greater than $1 \%$ of total leaf protein (DeRocher et al. 1991; Vierling 1991; Hsieh et al. 1992; Howarth and Ougham 1993; Arrigo and Landry 1994; O'Connell 1994). While most eukaryotes have just a few sHsps (15-35 kD), in plants this class has duplicated and diversified to include 20-50 different isoforms in most species (Vierling 1991; Arrigo and Landry 1994). Small Hsps (heat shock proteins) are usually divided into five classes based on sequence homology and subcellular localization; two classes are localized to the cytosol and one each to the chloroplast, mitochondria, and endoplasmic reticulum (Vierling 1991; Waters 1995; Waters et al. 1996). In vivo, sHsps occur as oligomeric complexes of 12-40 subunits ranging in total molecular mass from 200-800 kD (Behlke et al. 1991; Chen et al. 1994; Lee et al. 1995; Waters et al. 1996; Kim et al. 1998). Unlike many higher-molecular-mass Hsps, most sHsps are not constitutively expressed. Light, osmotic, salt, and oxidative stresses, in addition to high temperature and most other protein-denaturing stresses, can all lead to increased small heat shock protein (sHsp) expression (Vierling 1991; Harndahl et al. 1999; Hamilton and Heckathorn 2001).

\footnotetext{
${ }^{1}$ Author for correspondence; current address: Max-Planck-Institut für chemische Ökologie, Beutenberg Campus, Winzerlaer Strasse 10, D-07745 Jena, Germany; telephone 49-3641-643657; fax 49-3641643668; e-mail cknight@ice.mpg.de.
}

Manuscript received April 2002; revised manuscript received July 2002.
Expression of sHsp can be viewed both as a symptom of thermal stress and as a potential protective mechanism. A quantitative increase in the pool of denatured proteins in the cell, as well as increased membrane fluidity (Vigh et al. 1998), are thought to be primary signals of increased sHsp expression. Therefore, as levels of denatured proteins increase, so will sHsp expression, at least until critical temperatures for the heat deactivation of transcription and translation are reached. Accumulating evidence indicates that $\mathrm{sHsps}$ are important for the maintenance of photosynthetic and respiratory electron transport (Downs and Heckathorn 1998; Heckathorn et al. 1998 and in press; Miyao-Tokutomi et al. 1998; Downs et al. 1999a; Nakamoto et al. 2000). Studies comparing genotypes or species have shown that after identical temperature treatments, genotypes that accumulate greater levels of $\mathrm{sH}$ sps show greater protection of photosystem II (PS II) electron transport $\left(F_{\mathrm{v}} / F_{\mathrm{m}}\right.$; Preczewski et al. 2000; Knight and Ackerly 2001), which supports the hypothesis that sHsps play a protective role. In general it is thought that Hsps prevent irreversible aggregation of denatured proteins by binding and stabilizing exposed hydrophobic domains, a process that facilitates protein refolding following high temperature and other protein-denaturing stress (Jakob et al. 1993; Merck et al. 1993; Jinn et al. 1995; Lee et al. 1995, 1997; Laksanalamai et al. 2001). In addition to preventing protein aggregation, Hsps may also stabilize membranes and possibly act as site-specific antioxidants (Harndahl et al. 1999; Lee et al. 2000; Gustavsson et al. 2001; Hamilton and Heckathorn 2001; Torok et al. 2001).

The evolutionary conservation of sHsps, combined with their duplication and diversification in plants, has led to the hypothesis that sHsps may play an important role for plant 
adaptation across thermal gradients (Coleman et al. 1995; Downs et al. 1998). However, only a few studies have examined comparative sHsp responses between plant species from contrasting thermal environments (Downs et al. 1998; Knight and Ackerly 2001), and we are still far from a general consensus concerning predicted differences between thermophilic and mesophilic species (Vierling 1991; Feder and Hofmann 1999).

Most previous research on the sHsp response has involved studies of a single species. Those that have involved more than one genotype often rely on sHsp induction intensities after a single heat shock temperature (Downs et al. 1998; Preczewski et al. 2000). In addition, the method and duration of temperature treatments and the recovery period following temperature treatments all vary considerably between studies, making generalizations difficult.

Here we focus on temperature and time-course-dependent accumulation of sHsps between two closely related Encelia species: Encelia farinosa, a common species in the inland Mojave Desert, and Encelia californica, found only in the much cooler coastal sage habitat along the Pacific coast of southern North America (fig. 1). We also measure the chlorophyll fluorescence parameter $F_{\mathrm{v}} / F_{\mathrm{m}}$ in the context of sHsp accumulation because it is heat sensitive and correlated with photosynthesis and therefore a good independent measure of thermal stress and physiological performance. Shrub canopy temperatures can differ considerably between the habitats of these Encelia species. Knight and Ackerly (2002) show that canopy temperatures exceeding $45^{\circ} \mathrm{C}$ are frequent in the desert, while those temperatures are rarely experienced in the coastal habitat. Encelia shows dramatic thermal niche divergence and has been the subject of numerous studies in plant evolutionary physiology (Ehleringer and Clark 1988). Much of this research has focused on differences in leaf size and pubescence in relation to leaf energy balance (Ehleringer and Mooney 1978; Ehleringer 1988; Ehleringer and Cook 1990; Sandquist and Ehleringer 1997, 1998). Here we examine whether biochemical adaptation associated with the heat shock protein response contributes to adaptive differentiation in Encelia species radiating across thermal gradients.

\section{Material and Methods}

\section{Seed Collection and Common Garden Conditions}

A common garden of Encelia californica and Encelia farinosa was established from field-collected seeds as described in Knight and Ackerly (2002). Seeds from desert populations of E. farinosa were collected near the Desert Studies Center in the Mojave Desert in 1999 (operated by California State University; lat. $35^{\circ} 11^{\prime} \mathrm{N}$, long. $\left.116^{\circ} 4^{\prime} \mathrm{W}\right)$. Seeds from coastal populations of E. californica were collected in the summer of 1999 along the base of the Santa Monica Mountains between Santa Barbara and Malibu in California (approximate lat. $34^{\circ} 37^{\prime} \mathrm{N}$, long. $120^{\circ} 5^{\prime} \mathrm{W}$ ). The seeds were germinated in vermiculite and later transplanted to variable-grain-size sand in $20-\mathrm{cm}$ diameter and $50-\mathrm{cm}$ deep pots in a glasshouse at the plant growth facility on the campus of Stanford University. Fifty individuals of each species were arranged in a fully randomized block in the glasshouse. The mean temperature in the glasshouse was
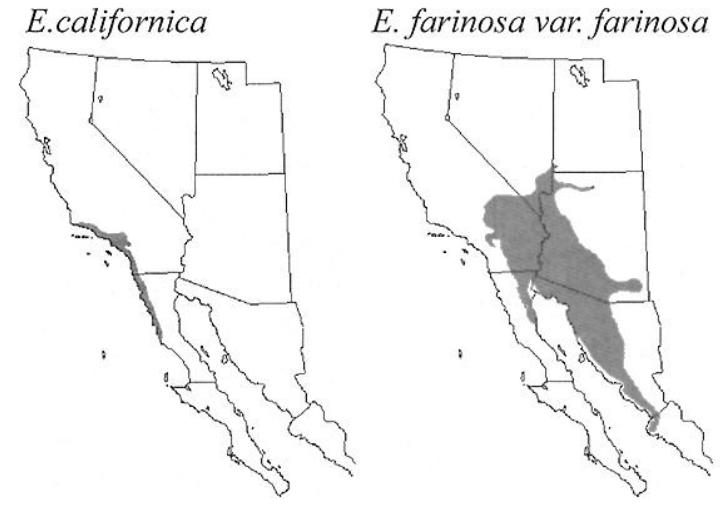

Fig. 1 The distribution of Encelia californica and Encelia farinosa var. farinosa in North America (maps from Clark 2000; used with permission).

$20^{\circ}-28^{\circ} \mathrm{C}$ during the day and ca. $15^{\circ} \mathrm{C}$ during the night. The plants were fertilized monthly, and the amount of nutrient addition was adjusted such that adequate growth and healthy foliage were maintained with minimal fertilizer. The amount of fertilizer added was identical between species. The plants matured in the common environment for over $1 \mathrm{yr}$ before we performed the first series of temperature treatments.

\section{Temperature-Dependent Accumulation of sHsps}

Temperature treatments were performed using detached leaves in air-circulating chambers that were submerged in temperature-controlled water baths. We used detached leaves because it was the only method available to achieve precise and constant leaf temperature control. Two series of temperature treatments were performed. The first was carried out at $42^{\circ}, 43^{\circ}, 44^{\circ}, 45^{\circ}, 46^{\circ}$, and $47^{\circ} \mathrm{C}$. Results from these treatments led us to run a second series at $33^{\circ}, 36^{\circ}, 38^{\circ}, 40^{\circ}, 42^{\circ}$, and $45^{\circ} \mathrm{C}$. Both series also involved a $28^{\circ} \mathrm{C}$ control (equivalent to the midday maximum temperature inside the glasshouse). The first series was replicated four times and the second three times. For each replicate, a random sample of leaves was collected early in the morning and then divided into seven groups of ca. 10-15 leaves (one group for each temperature). For each replicate of a temperature series, all temperature treatments for both species were performed simultaneously. For each temperature treatment, equal samples of both species were heat treated in the same chamber. Leaves were placed on top of a piece of moist filter paper within the chamber to prevent them from drying out during the temperature treatments. Leaf temperature measurements using thermocouples showed that within a chamber leaf temperatures did not vary by more than $0.1^{\circ} \mathrm{C}$. The difference between the water-bath temperature and leaf temperatures also did not vary by more than $0.1^{\circ} \mathrm{C}$. Temperature treatments lasted $4 \mathrm{~h}$. Leaves were allowed to recover for $4 \mathrm{~h}$ in the chambers under low light at room temperature. The last $30 \mathrm{~min}$ of the recovery period was in the dark. Following the recovery period, we quantified the dark-adapted photochemical efficiency of photosystem II using the chlorophyll fluorescence parameter, $F_{\mathrm{v}} / F_{\mathrm{m}}$, using a $0.7-\mathrm{s}$ saturating pulse of ca. 12,000 $\mu \mathrm{mol} \mathrm{m}^{-2} \mathrm{~s}^{-1}$ (Hansatech FMS2 fluorom- 
eter, King's Lynn, U.K.). The leaves were then frozen in liquid $\mathrm{N}$ and stored at $-80^{\circ} \mathrm{C}$ until protein extraction.

\section{Time Course of sHsp Accumulation}

Comparisons between the two Encelia species for the time course of sHsp accumulation were conducted following a 15$\min , 42^{\circ} \mathrm{C}$ heat treatment (which was close to the peak accumulation temperature for both species). Random samples from a large group of leaves heat shocked together were collected at the following time points: before the heat shock; immediately after; and then at 15, 45, 90, 180, and $360 \mathrm{~min}$. Both species were heat shocked in the same chamber. $F_{\mathrm{v}} / F_{\mathrm{m}}$ measurements were taken at each time point, except immediately after the heat shock (rapid relaxation of steady state fluorescence after heat stress makes measurements immediately after heat stress highly variable). The experiment was replicated three times.

\section{Protein Methods}

Total soluble leaf protein was extracted using a ceramic mortar and pestle in an extraction buffer consisting of $3 \% \mathrm{w} / \mathrm{v}$ SDS (sodium dodecyl sulfate), $10 \%$ v/v $1.5 \mathrm{M}$ Tris, $1 \%$ v/v 1 mM PMSF (phenylmethylsulfonyl fluoride), $2 \% \mathrm{v} / \mathrm{v} 0.1 \mathrm{M}$ EDTA (ethylenediaminetetraacetic acid), $0.5 \% \mathrm{v} / \mathrm{v} 1 \mathrm{M} \epsilon-$ amino-n-caproic acid, $1 \% \mathrm{v} / \mathrm{v} 1 \mathrm{M}$ benzamidine, $2 \% \mathrm{w} / \mathrm{v}$ PVP (polyvinylpyrrolidone), 4\% w/v PVPP (polyvinylpolypyrrolidone), $0.1 \% \mathrm{w} / \mathrm{v}$ DTT (Dithiothreitol), $0.2 \% \mathrm{w} / \mathrm{v}$ ascorbate, and $0.1 \% \mathrm{v} / \mathrm{v}$ of the protease inhibitors antipain and leupeptin (modified from Heckathorn et al. 1996). We found that the soluble protein concentration of the extracted sample varied considerably with the ratio of extraction buffer to fresh mass of leaf tissue and with the duration of incubation, mixing, and grinding with the extraction buffer. Therefore, for all samples we added $2 \mathrm{~mL}$ of the extraction buffer to $1 \mathrm{~g}$ of fresh leaf tissue and continued grinding the leaf tissue in the mortar and pestle for $10 \mathrm{~min}$ after pulverizing the leaf tissue in liquid $\mathrm{N}$. Samples were boiled for $4 \mathrm{~min}$, centrifuged for $15 \mathrm{~min}$ at 2100 $g$, International Equipment Company (IEC; Needham Heights, Mass.), and the supernatant was collected and stored at $-80^{\circ} \mathrm{C}$. The concentration of soluble protein extract was determined using a Coomassie dot blot on Whatman filter paper (\#4) and quantified using a Hewlett Packard ScanJet II laser scanner (Palo Alto, Calif.; after Ghosh et al. 1988 and Vincent et al. 1997). Sample concentrations were inferred from a standard curve of BSA serial dilutions of known concentration.

We used a polyclonal antibody that detects multiple sHsps in heat-stressed plant tissue (provided by S. A. Heckathorn). It was produced using an oligopeptide of the conserved heat shock domain found in all plant sHsps (as in Downs et al. 1998, except that the antiserum was raised in rabbits and the peptide was conjugated to kehole limpet hemocyanin [KLH]). The antibody cross-reacts with several sHsps between ca. 17 and $30 \mathrm{kD}$. Because we used one-dimensional electrophoresis, we could not quantify variation in the number of sHsps recognized. We also attempted to use a monoclonal antibody developed by Heckathorn et al. (1998) to detect a $22 \mathrm{kD}$ chloroplast sHsp; however, we were unable to detect the protein in either of these species using that antibody.

Forty micrograms of soluble protein were loaded on precast
5\%-20\% TRIS-glycine SDS-PAGE gels (BIO-RAD, Hercules, Calif.). A positive control (Ceanothus cuneatus heat shocked for $4 \mathrm{~h}$ at $42^{\circ} \mathrm{C}$ with a 4 -h recovery period) was run on each gel to account for blot-to-blot variation. Following separation, proteins were transferred to a polyvinylidene difluoride (PVDF) membrane by Western blot. Membranes were blocked for $2 \mathrm{~h}$ following transfer in a 1.5-M Tris $(\mathrm{pH} \mathrm{7.5),2 \%} \mathrm{w/v}$ powdered milk solution. The optimal antibody concentration was found by serial dilution so that resulting band intensities were within the linear range of detection. The PVDF membranes were incubated overnight at room temperature with a $1 / 3000$ dilution of the polyclonal sHsp antibody, followed by a 1.5-h incubation with a goat antirabbit IgG alkaline phosphatase conjugated secondary antibody (Sigma, St. Louis; $1 /$ 10,000 dilution). Following development with the alkaline phosphatase substrate, accumulation levels of sHsps were quantified using a Hewlett Packard ScanJet II and Scion Image for Windows (available at http://www.scioncorp.com). Levels of $\mathrm{sHsp}$ accumulation are expressed as a percentage of the positive control.

\section{Statistics}

Differences between species for the temperature-dependent accumulation of sHsps were analyzed by two-way ANOVA, with species and temperature as factors. We also used Scheffé post hoc tests to examine differences between species at selected high and low temperatures. The decline in $F_{\mathrm{v}} / F_{\mathrm{m}}$ was analyzed similarly. We used repeated-measures ANOVA to examine differences between species for the time course of sHsps accumulation following the $15-\mathrm{min}, 42^{\circ} \mathrm{C}$ heat shock and for $F_{\mathrm{v}} / F_{\mathrm{m}}$. All analyses were performed using DataDesk (Ithaca, N.Y.)

\section{Results}

\section{Temperature-Dependent Accumulation of sHsps}

There was a significant difference between Encelia farinosa and Encelia californica for the temperature-dependent accumulation of sHsps (interaction term for the two-way ANOVA, $F_{10,76}=2.81, P=0.005$; fig. $2 A$ ). At lower temperatures, $E$. californica accumulated greater levels of sHsps, while at higher temperatures $E$. farinosa accumulated more (significant differences for Scheffé post hoc tests are indicated in fig. $2 \mathrm{~A}$ ). Both species reached peak accumulation at $42^{\circ} \mathrm{C}$. Accumulation levels were not significantly different at $41^{\circ}$ or $42^{\circ} \mathrm{C}$. For temperatures above $42^{\circ} \mathrm{C}, E$. farinosa maintained greater electron transport efficiency $\left(F_{\mathrm{v}} / F_{\mathrm{m}}\right)$ than E. california, but at temperatures below $42^{\circ} \mathrm{C}, F_{\mathrm{v}} / F_{\mathrm{m}}$ was not significantly different between the two species (two-way ANOVA, $F_{1,261}=10.91$, $P=0.001)$. Significant differences for individual temperatures are indicated on figure $2 B$ (Scheffé post hoc tests). For both species, there was significant $\mathrm{sHsp}$ accumulation before $F_{\mathrm{v}} / F_{\mathrm{m}}$ dropped considerably (fig. 3). Above peak sHsp accumulation temperatures, $F_{\mathrm{v}} / F_{\mathrm{m}}$ and $\mathrm{sHsp}$ expression declined in parallel to zero.

In the common environment, E. californica grew faster that E. farinosa (data not presented). Nitrogen accumulation may have been greater for E. californica for the same nitrogen ad- 


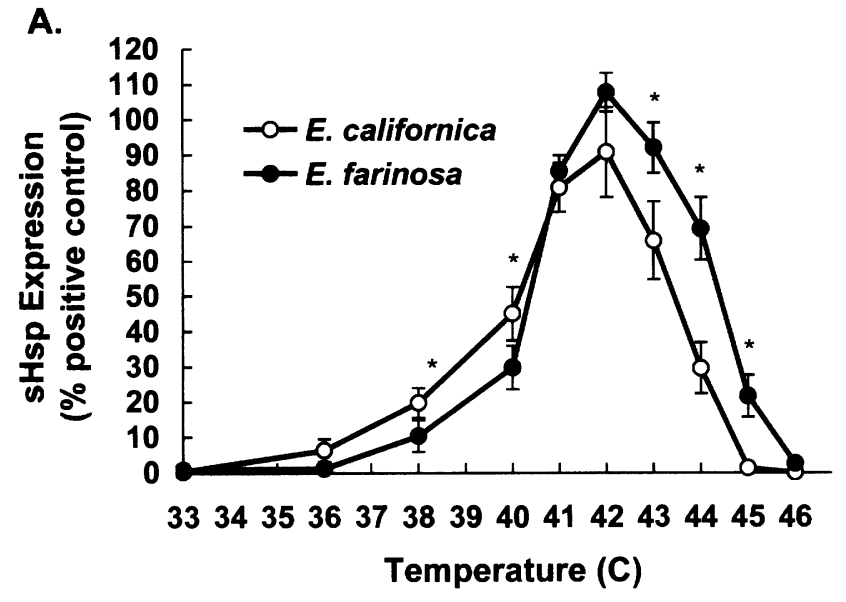

B.

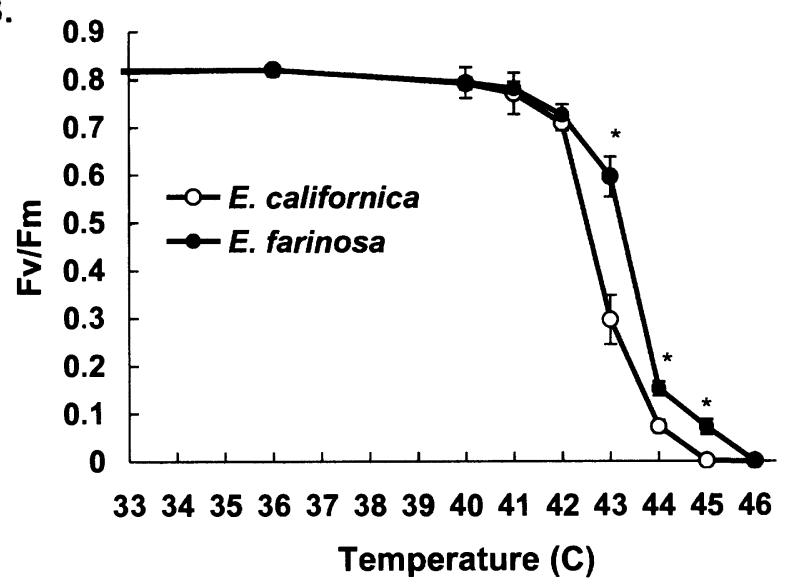

Fig. $2 A$, Contrasting patterns of temperature-dependent accumulation of small heat shock protein (sHsp) for Encelia farinosa and Encelia californica. Level of sHsp expression is a percentage of a positive control. $B$, Decline in photochemical efficiency of photosystem II $\left(F_{\mathrm{v}} / F_{\mathrm{m}}\right)$. Asterisks indicate responses that are significantly different between species by Scheffé post hoc tests following two-way ANOVAs. Data are means \pm 1 standard error.

dition level; however, E. farinosa showed no visible signs of stress.

\section{Time Course of sHsp Accumulation}

Repeated-measures ANOVA indicated that there was a significant interaction between species and sampling time after the heat shock for $\mathrm{sHsp}$ accumulation $\left(F_{6,24}=5.59, P=\right.$ $0.001)$. There was also a significant difference between species $\left(F_{1,24}=11.76, P=0.024\right)$ and between time points $\left(F_{6,24}=\right.$ 157.01, $P<0.001)$. Encelia californica had greater sHsp accumulation earlier than E. farinosa and by the end of the measurement period had nearly three times greater expression than E. farinosa (fig. 4). Encelia farinosa maintained significantly greater electron transport efficiency following the temperature treatments (repeated-measures ANOVA, $F_{1,24}=$ $8.43, P=0.01)$.

\section{Discussion}

When grown in a common environment and subjected to a series of temperature stresses, Encelia californica accumulated greater levels of sHsps at low temperatures $\left(38^{\circ}\right.$ and $\left.40^{\circ} \mathrm{C}\right)$, while Encelia farinosa accumulated greater levels at high temperatures $\left(43^{\circ}, 44^{\circ}\right.$, and $45^{\circ} \mathrm{C}$; fig. $\left.2 A\right)$. Interestingly, both species reached peak sHsp accumulation at $42^{\circ} \mathrm{C}$. It should be noted that leaf temperatures frequently exceed $42^{\circ} \mathrm{C}$ for $E$. farinosa in the desert; however, leaf temperatures are rarely that high for the coastal E. californica (Knight and Ackerly 2002).

We also found that $E$. californica accumulated greater levels of sHsps at all time points following a $15-\mathrm{min}, 42^{\circ} \mathrm{C}$ temperature treatment (fig. 4). Six hours after the heat shock, $E$. californica had accumulated nearly three times greater levels of sHsps than E. farinosa. These results indicate that while there are significant differences between species for the temperature-dependent accumulation of sHsps, the magnitude of these differences depends on the intensity and duration of thermal stress, as well as on the duration of recovery at less stressful temperatures. For example, after our 4-h heat shock at $42^{\circ} \mathrm{C}$ with $4 \mathrm{~h}$ of recovery time, there was not a significant difference between E. californica and E. farinosa for $\mathrm{sHsp}$ accumulation (fig. 3), but after the 15 -min heat shock at $42^{\circ} \mathrm{C}$, their responses were quite different (fig. 4).

Both species accumulated significant levels of sHsps at temperatures below the point at which significant reductions in PS II electron transport efficiency occur $\left(F_{\mathrm{v}} / F_{\mathrm{m}} ;\right.$ fig. 3$)$. This

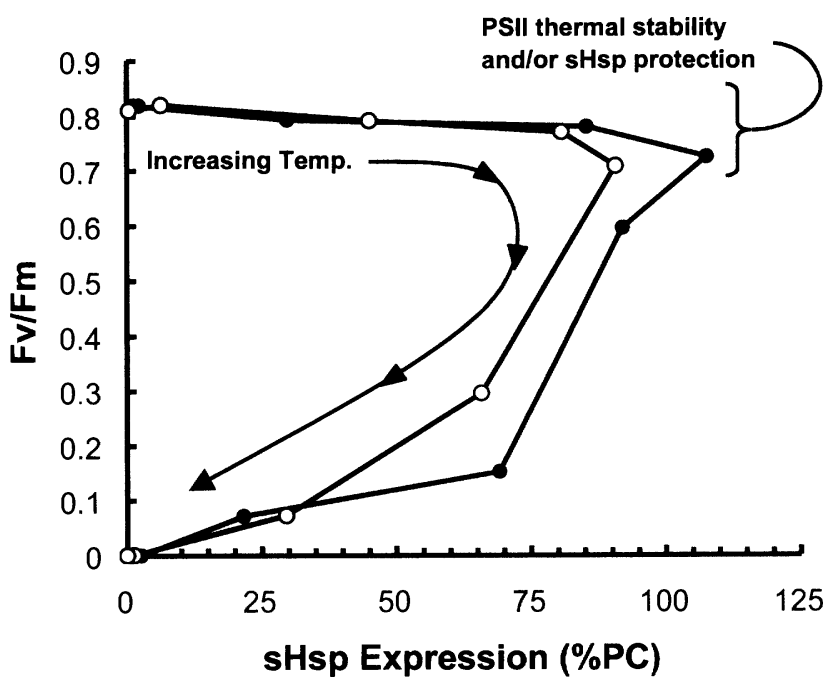

Fig. 3 Relationship between small heat shock protein (sHsp) expression and $F_{\mathrm{v}} / F_{\mathrm{m}}$ for the temperature treatments $\left(28^{\circ}-46^{\circ} \mathrm{C}\right.$; see fig. 2) for Encelia californica (open circles) and Encelia farinosa (filled circles). (For each species, lines connect adjacent temperature treatments starting at $28^{\circ} \mathrm{C}$ at the upper left corner, moving to the right to $42^{\circ} \mathrm{C}$ [peak sHsp accumulation temperature for both species], then down to the bottom left at $45^{\circ}$ and $46^{\circ} \mathrm{C}$.) Both species accumulate significant levels of sHsps before significant reductions in photosystem II (PSII) electron transport efficiency $\left(F_{\mathrm{v}} / F_{\mathrm{m}}\right)$. Levels of sHsps are a percentage of a positive control. Refer to fig. 2 for standard errors of these data. 
A.

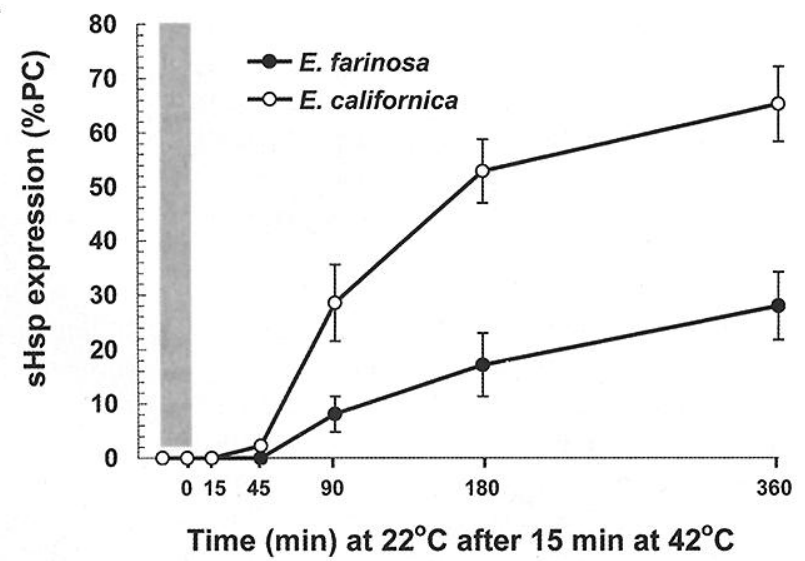

B.

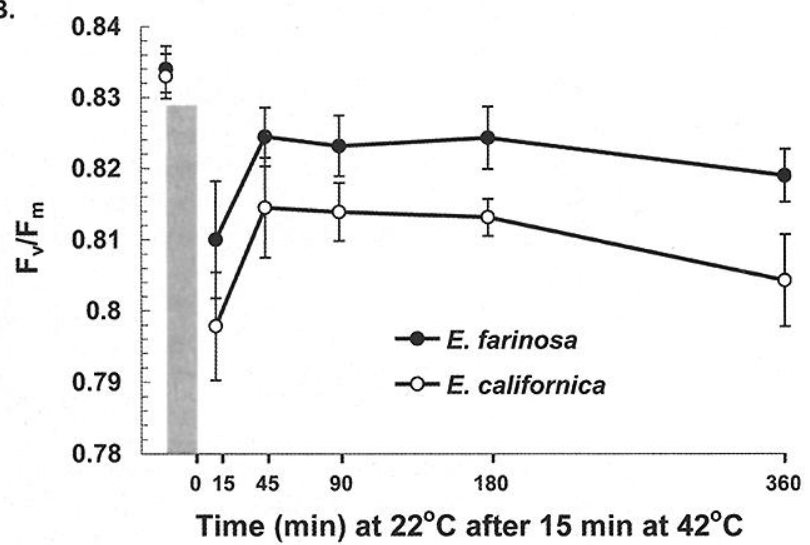

Fig. $4 A$, Time course ( $\mathrm{min}$ ) of small heat shock protein (sHsp) accumulation at $22^{\circ} \mathrm{C}$ after 15 -min, $42^{\circ} \mathrm{C}$ temperature treatments for Encelia californica (open circles) and Encelia farinosa (closed circles). Levels of sHsps are a percentage of a positive control. $B$, Recovery of $F_{\mathrm{v}} / F_{\mathrm{m}}$ for the same time points. Measurements before the heat stress are also indicated. The gray bar represents the 15-min heat shock. Time 0 is immediately after the heat shock. Data are means \pm 1 standard error.

observation may support the protective role of sHsps, but we cannot rule out the possibility that PS II is thermally stable to these temperatures independent of sHsp synthesis. Above peak accumulation, temperatures for $\mathrm{sH}$ sp synthesis, sHsp expression, and $F_{\mathrm{v}} / F_{\mathrm{m}}$ declined in parallel to zero. The sHsps may serve a protective role at these temperatures; however, the observed pattern may also represent correlated symptomatic responses to the heat stress.

After the 15 -min, $42^{\circ} \mathrm{C}$ heat shock, the mesophilic E. californica accumulated much greater levels of sHsps than the thermophylic E. farinosa but still had lower $F_{v} / F_{m}$ (fig. $4 A$, $4 B$ ). These results indicate that correlations between sHsp expression and photosynthetic or whole-plant thermotolerance among genotypes may depend critically on the measurement temperature; linear correlations for photosynthetic thermotolerance and $\mathrm{sHsp}$ accumulation after a single temperature treatment may be an oversimplification. In addition, because leaf temperatures are highly variable in natural environments, responses to short-duration high temperature stress may have cumulative effects, especially if costly plastic acclimatory adjustments are induced.

The results for sHsp expression presented here rely on immunological staining of Western blots. Because equal micrograms of soluble protein were run for all species, optimized extraction protocols were identical between species, and no sHsps were detected at lower temperatures, we feel that our results reflect intrinsic differences for inducible sHsp synthesis. There remains the possibility that differences in antigenicity contributed to experimental error and could lead to misleading results. However, antigenicity variation should be minimal because of the conserved nature of the sHsp domain in plants (Waters 1995; Waters et al. 1996). Also, because the sHsp antibody that we used cross-reacts with several sHsps, the integrated response may be more representative than for immunological studies that focus on just one epitope; some epitopes may be more or less antigenic for the sHsp antibody, but here we assume that antigenicity differences between sHsp epitopes are random.

According to current models, as the pool of denatured proteins increases, levels of Hsps expression also increase. These signal transduction pathways have been described in most detail for Hsp70 and Hsp90; however, the induction of sHsps may involve similar mechanisms and perhaps the same heat shock transcription factors (HSFs; Hubel et al. 1995). In the absence of protein-denaturing stresses, it is thought that HSFs are bound to Hsps, while in the presence of denatured proteins, Hsps are recruited to hydrophobic regions of denatured proteins and in the process release HSFs (Wu 1995; Morimoto 1998). HSFs then bind to the promoting elements of Hsp genes (often after forming trimers with other HSFs), leading to increased heat shock protein (Hsp) expression. If this model is correct, our observations indicate that the thermophilic $E$. farinosa may have had quantitatively less denatured protein after our lower temperature heat shocks, as well as after the 15min, $42^{\circ} \mathrm{C}$ heat shock. The evolution of thermotolerance may thus involve increased individual protein thermostability, which would be reflected in the temperature-dependent accumulation of sHsps. There are several proposed mechanisms to achieve increased individual protein thermal stability, including increased hydrogen bonds or salt bridges, optimized hydrophobic interactions, the replacement of amino acids with energetically unfavorable or thermally labile conformations, the shortening and stabilization of solvent exposed loops, an increase in the content and stability of $\alpha$-helices, and reduced protein masses (Sterner and Liebl 2001 for a recent review).

Variation among species and among artificially selected crop genotypes for sHsp accumulation has been found to be positively correlated with photosynthetic or whole-plant thermotolerance (Ougham and Stoddart 1986; Krishman et al. 1989; Colombo et al. 1992; Weng and Nguyen 1992; Frova and Gorla 1993; Park et al. 1996, 1997; Joshi et al. 1997; Ristic et al. 1998; Heckathorn et al. 1999; Preczewski et al. 2000; Knight and Ackerly 2001). However, it should be noted that several studies have found no relationship (Fender and O'Connell 1989; Frova and Gorla 1993; O'Connell 1994). In all cases, these studies have almost exclusively relied on levels of sHsp accumulation following a single temperature treatment. Here we demonstrate that correlations between photosynthetic thermal tolerance and $\mathrm{sHsp}$ expression may be 
positive, negative, or not significant, depending on the measurement temperature or the recovery time following heat stress.

Other studies have examined variation in Hsp accumulation in relation to the native thermal environment of species. Downs et al. (1998) sampled a broad taxonomic group and found that most species synthesized the chloroplast sHsp following a $40^{\circ} \mathrm{C}$ temperature treatment and that species from warmer climates accumulated greater concentrations of the chloroplast sHsp than species from cooler climates. However, Knight and Ackerly (2001) found no correlation between expression levels of the chloroplast $\mathrm{Hsp}$ following a $45^{\circ} \mathrm{C}$ temperature treatment and the mean environmental conditions within the geographic ranges of eight Ceanothus species. The results presented here from the Encelia congeners indicate that mesophilic species may accumulate more sHsps at low temperatures, while thermophilic species may have higher induction temperatures and greater sHsp accumulation at high temperatures, a pattern which has been previously observed for closely related marine snails from contrasting thermal environments (Tomanek and Somero 1999).

Considering the high energetic costs of protein synthesis, the maintenance of proteins in their native configuration, or in folding-competent states, is favorable to new synthesis (Sterner and Liebl 2001). In general, it is thought that sHsps, like many higher-molecular-mass Hsps, prevent irreversible aggregation of denatured proteins, thereby facilitating protein refolding following denaturing stresses (Jakob et al. 1993; Merck et al. 1993; Jinn et al. 1995; Lee et al. 1995, 1997; Ehrnsperger et al. 1999). While the specific functions of most sHsps remain elusive, accumulating evidence indicates that both the chloroplast and mitochondrial sHsps are important for the maintenance of photosynthetic and respiratory electron transport during and after high temperature stress (Heckathorn et al. 1998, 1999; Downs et al. 1999b; Hamilton and Heckathorn 2001), perhaps by preferential binding and stabilization of proteins involved in oxygen evolution and electron transport.

The proliferation of sHsps in plants is intriguing. Some stud- ies suggest smaller proteins are more thermally stable (Thompson and Eisenberg 1999; Chakravarty and Varadarajan 2000), probably in part from a reduced entropy gain of unfolding (Ganesh et al. 1999). This fact may contribute to the duplication and diversification of sHsps as a thermal protective mechanism in plants; sHsps themselves must be able to function at high temperatures, requiring mechanisms for their own thermal stability.

As in any organism, whole-plant thermotolerance is the result of the functional integration of many traits, including short time scale reversible plastic traits (such as Hsp expression or rapid changes in leaf angle) and traits that are either plastic but less reversible (such as leaf size) or genetically fixed or canalized traits that are not plastic (such as cuticle thickness). For example, E. farinosa has very low leaf absorptance because of a thick pubescent trichome layer on the upper leaf surface that positively affects leaf energy balance (Ehleringer and Mooney 1978; Ehleringer 1988; Ehleringer and Cook 1990; Sandquist and Ehleringer 1997, 1998). These adaptations in leaf morphology and pubescence may play a significant role for the evolution of increased thermal tolerance in Encelia. Here we show that biochemical evolution of the sHsp response may also contribute to the adaptive radiation of Encelia species across thermal gradients.

\section{Acknowledgments}

We thank Veronica Yovovich and Claire Phillips for help with protein extraction and quantification; Scott Heckathorn for assistance with protein methods and for providing the primary antibody; and George Somero, Katherine Preston, and Radika Bhaskar for critical reviews of the manuscript. This study was supported in part from a Tri-Agency (Department of Energy, National Science Foundation [NSF], USDA) Training Grant in Plant Biology, an NSF Dissertation Improvement Grant (IBN-9902295), and a fellowship from the Center for Evolutionary Studies at Stanford University (C. Knight).

\section{Literature Cited}

Arrigo AP, J Landry 1994 Expression and function of the lowmolecular-weight heat shock proteins. Cold Spring Harbor Monogr Ser 26:335-373.

Behlke J, G Lutsch, M Gaestel, H Bielka 1991 Supramolecular structure of the recombinant murine small heat shock protein hsp25. FEBS Lett 288:119-122.

Chakravarty S, R Varadarajan 2000 Elucidation of determinants of protein stability through genome sequence analysis. FEBS Lett 470 : 65-69.

Chen Q, K Osteryoung, E Vierling 1994 A 21-kDa chloroplast heat shock protein assembles into high molecular weight complexes in vitro and in organelle. J Biol Chem 269:13216-13223.

Clark C 2000 Encelia and its relatives. http://www.csupomona.edu/ jicclark/encelia.

Coleman JS, SA Heckathorn, RL Hallberg 1995 Heat-shock proteins and thermotolerance: linking molecular and ecological perspectives. Trends Ecol Evol 10:305-306.

Colomobo SJ, ML Colclough, VR Timmer, E Blumwald 1992 Clonal variation in heat tolerance and heat shock protein expression in black spruce. Silvae Genet 41:234-239.
Derocher AE, KW Helm, LM Lauzon, E Vierling 1991 Expression of a conserved family of cytoplasmic low molecular weight heat shock proteins during heat stress and recovery. Plant Physiol (Rockv) 96: 1038-1046.

Downs CA, JS Coleman, SA Heckathorn $1999 a$ The chloroplast 22$\mathrm{Ku}$ heat shock protein: a lumenal protein that associates with the oxygen evolving complex and protects photosystem II during heat stress. J Plant Physiol 155:477-487.

Downs CA, SA Heckathorn 1998 The mitochondrial small heat shock protein protects NADH: ubiquinone oxioreductase of the electron transport chain during heat stress in plants. FEBS Lett 430: 246-250.

Downs CA, SA Heckathorn, JK Bryan, JS Coleman 1998 The methionine-rich low-molecular-weight chloroplast heat-shock protein: evolutionary conservation and accumulation in relation to thermotolerance. Am J Bot 5:175-183.

Downs CA, SL Ryan, SA Heckathorn $1999 b$ The chloroplast small heat-shock protein: evidence for a general role in protecting photosystem II against oxidative stress and photoinhibition. J Plant Physiol 155:488-496. 
Ehleringer JR 1988 Comparative ecophysiology of Encelia farinosa and Encelia frutescence. I. Energy balance considerations. Oecologia 76:553-561.

Ehleringer JR, C Clark 1988 Evolution and adaptation in Encelia Asteraceae. Pages 221-248 in LD Gottlieb, SK Jain, eds. Plant evolutionary biology. Chapman \& Hall, New York.

Ehleringer JR, CS Cook 1990 Characteristics of Encelia species differing in leaf reflectance and transpiration under common garden conditions. Oecologia 82:484-489.

Ehleringer JR, HA Mooney 1978 Leaf hairs: effects on physiological activity and adaptive value to a desert shrub. Oecologia 37:183-200.

Ehrnsperger M, H Lilie, M Gaestel, J Buchner 1999 The dynamics of the Hsp25 quaternary structure: structure and function of different oligomeric species. J Biol Chem 274:14867-14873.

Feder ME, GE Hofmann 1999 Heat-shock proteins, molecular chaperones, and the stress response: evolutionary and ecological physiology. Annu Rev Physiol 61:243-282.

Fender SE, MA O'Connell 1989 Heat shock protein expression in thermotolerant and thermosensitive lines of cotton. Plant Cell Rep 8:37-40.

Frova C, MS Gorla 1993 Quantitative expression of maize HSPs genetic dissection and association with thermotolerance. Theor Appl Genet 86:213-220.

Ganesh C, N Eswar, S Srivastava, C Ramakrishnan, R Varadarajan 1999 Prediction of the maximal stability temperature of monomeric globular proteins solely from amino acid sequence. FEBS Lett 454:31-36.

Ghosh SS, S Gepstein, J Heikkila, EB Dumbroff 1988 Use of a scanning densitometer or an ELISA plate reader for measurement of nanogram amounts of protein in crude extracts from biological tissue. Ann Biochem 169:227-233.

Gustavsson N, BP Kokke, B Anzelius, WC Boelens, C Sundby 2001 Substitution of conserved methionines by leucines in chloroplast small heat shock protein results in loss of redox-response but retained chaperone-like activity. Protein Sci 10:1785-1793.

Hamilton WE, SA Heckathorn 2001 Mitochondrial adaptations to $\mathrm{NaCl}$ complex I is protected by anti-oxidants and small heat shock proteins, whereas complex II is protected by proline and betanine. Plant Physiol 126:1266-1274.

Harndahl U, RB Hall, KW Osteryoung, E Vierling, JF Bornman, C Sundby 1999 The chloroplast small heat shock protein undergoes oxidation-dependent conformational changes and may protect plants from oxidative stress. Cell Stress Chaperones 4:129-138.

Heckathorn SA, CA Downs, JS Coleman 1999 Small heat shock proteins protect electron transport in chloroplasts and mitochondria during stress. Am Zool 39:865-876.

Heckathorn SA, CA Downs, TD Sharkey, JS Coleman 1998 The small methionine-rich chloroplast heat-shock protein protects photosystem II electron transport during heat stress. Plant Physiol 116: 439-444.

Heckathorn SA, GJ Poeller, JS Coleman, RL Hallberg 1996 Nitrogen availability and vegetative development influence the response of ribulose 1,5-bisphosphate carboxylase/oxygenase, phosphoenolpyruvate carboxylase, and heat-shock protein content to heat stress in Zea mays L. Int J Plant Sci 157:546-553.

Heckathorn SA, SL Ryan, JA Baylis, D Wang, EW Hamilton, L Cundiff, DS Luthe In press In vivo evidence from Agrostis stolonifera selection genotype that a chloroplast small heat-shock protein can protect photosystem II during heat stress. Funct Plant Biol.

Howarth CJ, HJ Ougham 1993 Tansley review 51: gene expression under temperature stress. New Phytol 125:1-26.

Hsieh MH, JT Chen, TL Jinn, YM Chen, CY Lin 1992 A class of soybean low molecular weight heat shock proteins: immunological study and quantitation. Plant Physiol 99:1279-1284.

Hubel A, JH Lee, C Wu, F Schoffl 1995 Arabidopsis heat shock fac- tor is constitutively active in Drosophila and human cells. Mol Gen Genet 248:136-141.

Jakob U, M Gaestel, K Engel, J Buchner 1993 Small heat shock proteins are molecular chaperones. J Biol Chem 268:1517-1520.

Jinn TM, YM Chen, CY Linn 1995 Characterization and physiological function of class I-low molecular-mass-heat-shock protein complex in soybean. Plant Physiol 108:693-701.

Joshi CP, NY Klueva, KJ Morrow, HT Nugyen 1997 Expression of a unique plastid localized heat-shock protein is genetically linked to acquired thermotolerance in wheat. Theor Appl Genet 95:834-841.

Kim R, KK Kim, H Yokota, SH Kim 1998 Small heat shock protein of Methanococcus jannaschii, a hyperthermophile. Proc Natl Acad Sci USA 95:9129-9133.

Knight CA, DD Ackerly 2001 Correlated evolution of chloroplast heat shock protein expression in closely related plant species. Am J Bot 88:411-418.

2002 An ecological and evolutionary analysis of photosynthetic thermotolerance using the temperature dependent increase in fluorescence. Oecologia 130:505-514.

Krishman M, HT Nguyen, JJ Burke 1989 Heat shock protein synthesis and thermal tolerance in wheat. Plant Physiol (Rockv) 90: 140-145.

Laksanalamai P, DL Maeder, RT Robb 2001 Regulation and mechanism of action of the small heat shock protein from the hyperthermophilic archaeon Pyrococcus furiosus. J Bacteriol 183:51985202.

Lee $\mathrm{BH}$, SH Won, HS Lee, M Miyao, WI Chubg, IJ Kim, J Jo 2000 Expression of the chloroplast localized small heat-shock protein by oxidative stress in rice. Gene 245:283-290.

Lee GJ, N Pokala, E Vierling 1995 Structure and in vitro molecular chaperone activity of cytosolic small heat shock proteins from pea. J Biol Chem 270:10432-10438.

Lee GJ, AM Roseman, HR Saibil, E Vierling 1997 A small heat shock protein stably binds heat-denatured model substrates and can maintain a substrate in a folding competent state. EMBO (Eur Mol Biol Organ) J 16:659-671.

Merck KB, PJTA Groenen, CEM Vooter, WA De Haard Hoekman, J Horwitz, H Bloemendal, WW De Jong 1993 Structural and functional similarities of bovine alphs crystalline and mouse small heatshock protein: a family of chaperones. J Biol Chem 268:1046-1052.

Miyao-Tokutomi M, BH Lee, N Mizusawa, and N Yamamoto 1998 Active oxygen and photoinhibition of photosystem II. Pages 2097-2102 in Proceedings of the XI International Congress on Photosynthesis. Kluwer Academic, Dordrecht.

Morimoto RI 1998 Regulation of the heat shock transcriptional response: cross talk between a family of heat shock factors, molecular chaperones, and negative regulators. Genes Dev 12:3788-3796.

Nakamoto H, N Suzuki, SK Roy 2000 Constitutive expression of a small heat shock protein confers cellular thermotolerance and thermal protection to the photosynthetic apparatus in cyanobacteria. FEBS Lett 483:169-174.

O'Connell MA 1994 Heat shock proteins and thermotolerance. Pages 163-183 in AS Basra, ed. Stress-induced gene expression in plants. Harwood, Chur.

Ougham HJ, JL Stoddart 1986 Synthesis of heat-shock protein and acquisition of thermotolerance in high-temperature tolerant and high-temperature susceptible lines of Sorghum bicolor. Plant Physiol 44:163-168.

Park SK, R Chang, R Shivaji, DS Luthe 1997 Recovery from heat shock in heat tolerant and non-heat tolerant variants of creeping bentgrass. Plant Physiol 115:229-240.

Park SK, R Shivaji, JV Krans, DS Luthe 1996 Heat-shock response in heat-tolerant and nontolerant variants of Agrostis palustris Huds. Plant Physiol 111:515-524.

Preczewski PJ, SA Heckathorn, CA Downs, JS Coleman 2000 Photosynthetic thermotolerance is quantitative and positively cor- 
related with production of specific heat shock proteins among nine genotypes of Lycopersicon (tomato). Photosynthetica 38:127-134.

Ristic Z, G Yang, B Martin, S Fullerton 1998 Evidence of association between specific heat-shock protein(s) and the drought and heart tolerance phenotype in maize. J Plant Physiol 153:497-505.

Sandquist DR, JR Ehleringer 1997 Intraspecific variation of leaf pubescence and drought response in Encelia farinosa: genetic differentiation associated with contrasting desert environments. New Phytol 135:635-644.

1998 Intraspecific variation of drought adaptation in brittlebush: leaf pubescence and timing of leaf loss vary with rainfall. Oecologia 113:162-169.

Sterner R, W Leibl 2001 Thermophilic adaptation of proteins. Crit Rev Biochem Mol Biol 36:39-106.

Thompson MJ, D Eisenberg 1999 Transproteomic evidence of a loopdeletion mechanism for enhancing protein thermostability. J Mol Biol 290:595-604.

Tomanek L, GN Somero 1999 Evolutionary and acclimation-induced variation in the heat-shock responses of congeneric marine snails (genus Tegula) from different thermal habitats: implications for limits of thermotolerance and biogeography. J Exp Biol 202:29252936.

Török Z, P Goloubinoff, I Horváth, NM Tsvetkova, A Glatz, G
Balogh, V Varvasovszki, et al 2001 Synechocystis HSP17 is an amphitropic protein that stabilizes heat-stressed membranes and binds denatured proteins for subsequent chaperone-mediated refolding. Proc Natl Acad Sci USA 98:3098-3103.

Vierling E 1991 The roles of heat shock proteins in plants. Annu Rev Plant Physiol 42:579-620.

Vigh L, B Maresca, JL Harwood 1998 Does the membrane's physical state control the expression of heat shock and other genes? Trends Biochem Sci 23:369-374.

Vincent SG, PR Cunningham, NL Stephens, AJ Halayko, JT Fisher 1997 Quantitative densitometry of proteins stained with Coomassie blue using a Hewlett Packard scanjet scanner and Scanplot software. Electrophoresis 18:67-71.

Waters ER 1995 The molecular evolution of the small heat shock proteins in plants. Genetics 141:785-795.

Waters ER, GJ Lee, E Vierling 1996 Evolution, structure and function of the small heat shock proteins in plants. J Exp Biol 47:325-338.

Weng J, HT Nguyen 1992 Expression of a conserved family of cytoplasmic low molecular weight heat shock proteins during heat stress and recovery. Theor Appl Genet 84:941-946.

Wu C 1995 Heat shock transcription factors: structure and regulation. Annu Rev Cell Dev Biol 11:441-469. 